\title{
Pegada ecológica de alunos do Programa de Pós- Graduação em Desenvolvimento e Meio Ambiente da Universidade Federal do Ceará, Brasil
}

\section{Maria Laudecy Ferreira de Carvalho ${ }^{1}$, Juliana Cardozo de Farias $^{2}$, Patrícia Verônica Pinheiro Sales Lima ${ }^{3}$, Ivanilza Moreira de Andrade ${ }^{4}$ e Ana Bárbara de Araújo Nunes ${ }^{5}$}

\author{
${ }^{1}$ Universidade Federal da Paraíba. Programa de Pós-Graduação em \\ Desenvolvimento e Meio Ambiente (PRODEMA). Campus I. João Pessoa-PB, Brasil \\ (CEP 58051-900). E-mail: laudecyferreira@gmail.com. \\ ${ }^{2}$ Universidade Federal do Piauí. Programa de Pós-Graduação em Desenvolvimento \\ e Meio Ambiente (PRODEMA). Campus Universitário Ministro Petrônio Portella. \\ Teresina-PI, Brasil (CEP 64049-550). \\ ${ }^{3}$ Universidade Federal do Ceará. Programa de Pós-Graduação em Desenvolvimento \\ e Meio Ambiente (PRODEMA). Campus do Pici. Bloco 902. Fortaleza-CE, Brasil (CEP \\ 60455-970). \\ ${ }^{4}$ Universidade Federal do Piauí. Campus Universitário Ministro Petrônio Portella. - \\ Teresina-PI, Brasil (CEP 64049-550). \\ 5Universidade Federal do Ceará. Departamento de Engenharia Hidráulica e \\ Ambiental. Campus do Pici. Bloco 713. Fortaleza- CE, Brasil (CEP 60440-970).
}

Resumo. A pegada ecológica vem sendo utilizada como uma ferramenta para medir a biocapacidade da terra em relação às demandas humanas. Destarte, neste trabalho estimou o nível de sustentabilidade dos discentes da Pós-Graduação em Desenvolvimento e Meio Ambiente da Universidade Federal do Ceará, através do Indicador Pegada Ecológica. Este indicador é utilizado para medir quantos hectares uma pessoa necessita para produzir o que consome por ano de maneira sustentável. A metodologia utilizada baseou-se na aplicação junto aos referidos alunos, no modelo de questionário do WWF. Os resultados sinalizam que, a maioria dos discentes deveriam reavaliar seus valores e alterar seu comportamento em relação ao padrão de consumo. Ainda, que sem a mudança de valores e posteriormente da postura da sociedade, não há como vivermos de acordo com a biocapacidade ecológica que o planeta pode suportar.

Palavras-chave: Indicadores de sustentabilidade; Biocapacidade; Padrões de consumo; Discentes.

Abstract. Ecological footprint of the students of the Graduate Program in Development and Environment of the Federal University of Ceará, Brazil. The ecological footprint has been used as a tool to measure the biocapacity of the earth in relation to human demands. Thus, in this work estimated the level of

Recebido $17 / 11 / 2019$

Aceito $28 / 12 / 2019$

Publicado $31 / 12 / 2019$

Acesso aberto

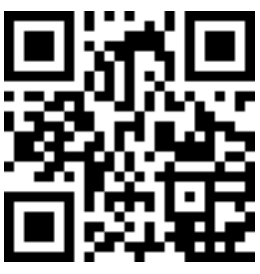


sustainability of students of the Graduate in Development and Environment of the Federal University of Ceará (UFC), through the Ecological Footprint Indicator. This indicator is used to measure how many hectares a person needs to produce what they consume per year in a sustainable manner. The methodology used was based on the application to these students, in the questionnaire model of WWF. The results indicate that most students should reassess their values and change their behavior in relation to the consumption pattern. Still, that without the change of values and later the posture of society, there is no way to live according to the ecological biocapacity that the planet can support.

Keywords: Sustainability indicators; Biocapacity; Consumer patterns; Students.

\section{Introdução}

0 crescente consumo e a degradação ambiental ocasionados pelo modelo de crescimento econômico tem gerado enormes desequilíbrios. Frente a essa realidade, pesquisadores de todo o mundo têm proposto soluções no sentido da sustentabilidade (Guimaraes, 1991).

Dentre as metodologias que acompanham o equilíbrio ambiental, a pegada ecológica é um dos indicadores de sustentabilidade que mede o impacto do homem no ambiente (Bellen, 2007). Esse indicador converte a quantidade de matéria-prima empregada ou o dióxido de carbono emitido, na quantidade de solos e recursos hídricos bioprodutivos necessário para manter esses recursos.

A Pegada Ecológica (PE) é uma das ferramentas de avaliação de sustentabilidade mais sugeridas e difundidas no mundo. 0 princípio básico desse indicador apresentada por Rees e Wackernagel (1996), em seu livro Ecological Footprint (EF), é que todo indivíduo ou região, ao desenvolver seus diferenciados processos, tem um impacto sobre o Planeta, quando utiliza os recursos e gera desperdícios (Lisboa e Barros, 2010).

\author{
(D) 0000-0002-486-8997 \\ Maria Laudecy \\ Ferreira de Carvalho \\ (D) 0000-0002-6622-3640 \\ Juliana Cardozo de \\ Farias \\ D 0000-0002-3527-1826 \\ Patrícia Verônica \\ Pinheiro Sales Lima \\ (D) 0000-0001-5845-6252 \\ Ivanilza Moreira de \\ Andrade \\ (1) 0000-0001-6059-8540 \\ Ana Bárbara de Araújo \\ Nunes
}

Tais impactos no Planeta podem ser gerados de uma maneira sintética quando cada indivíduo faz suas opções enquanto consumidores, na maneira como se desloca, na quantidade de resíduos que é produzido e até o tipo de alimento que se consome, todas essas atividades demandam uma determinada porção de recursos do ambiente natural para a sua manutenção (Firmino et al., 2009).

As categorias de espaço do ambiente natural utilizadas para $o$ cálculo desse indicador são classificadas como áreas de cultivo, de pasto e de floresta. Quanto maior o consumo de recursos naturais e a produção de resíduos, maior será a pegada ecológica. Isto implica em um maior uso por áreas de terra para garantir a manutenção das atividades humanas (Firmino et al., 2009).

De acordo com dados do relatório "Planeta Vivo 2018", nos últimos 50 anos, a Pegada Ecológica mundial aumentou cerca de 190\% (Grooten e Almond, 2018). Isto é atribuído à superexploração e a constante expansão da agricultura que são impulsionadas pelo consumo humano descontrolado. 
Sabendo que a PE tem crescido nos últimos anos e que sua variação se deve a diferentes estilos de vida e padrões de consumo, e que a educação pode influenciar nesses aspectos, objetivou-se aplicar o cálculo da PE com discentes matriculados na PósGraduação em Desenvolvimento e Meio Ambiente, na Universidade Federal do Ceará, em Fortaleza, a fim de conhecer os padrões atuais de consumo desse grupo.

\section{0 cálculo da pegada ecológica}

0 método para o cálculo da pegada ecológica é baseado na capacidade de carga ou de suporte e é calculada somando-se a contribuição de vários elementos, que são as parcelas de impactos ambientais. Ao adicionar as várias parcelas é obtido um valor global que representa um espaço produtivo capaz de repor, pelo menos em Teoria, o capital natural consumido pela humanidade (Wackernagel e Rees, 1996; Bellen, 2007). Com o cálculo da pegada ecológica estima-se o consumo pessoal médio anual a partir dos dados agregados do consumo tais como local, regional ou nacional.

Este índice pode ser utilizado em vários âmbitos (organizacional, individual, familiar, local, nacional, regional e global) para avaliação ambiental (Firmino et al., 2009). De acordo com Dias (2002) a pegada ecológica mede quantos hectares uma pessoa necessita para produzir o que consome por ano, ou seja, é um indicador de nosso consumo de recursos naturais. Tal indicador contabilizando os fluxos de matéria e os resíduos que produzimos em um sistema econômico, convertendoos em área correspondente de terra ou recursos hídricos de um sistema. Ainda para Dias (2002) é importante perceber o ponto limítrofe da capacidade ecológica do planeta, isto significa saber até que período o referido planeta é suficiente:

"as mudanças induzidas pelo ser humano ocorrem mais rapidamente e são, geralmente, mais difíceis de serem revertidas. Resolver essas disparidades é o único caminho para se assegurar um futuro mais sustentável para o planeta e para a sociedade" (Dias, 2002, p. 39).

Desta forma, a PE estima o nível de desenvolvimento sustentável necessário para garantir a sobrevivência de uma população ou sistemas econômicos, fornecimento de energia e recursos naturais. Além disso, visa a assegurar a capacidade de absorção de resíduos produzidos pelo sistema (Wackernagel e Rees, 1996).

A estimativa da PE agrupa indicadores com valores culturais, tecnológicos e elementos econômicos de uma dada área. No entanto, não é possível estimar a demanda para todos os bens de consumo e serviços, pois os cálculos se reduzem apenas às categorias mais relevantes. Existem algumas limitações desse indicador, uma delas é que o mesmo enfoca apenas a dimensão ecológica e recua bastante nas análises nas esferas social e econômica. Apesar disso, esse indicador tem sido amplamente utilizado e apresenta uma grande abrangência até $o$ momento (Lisboa e Barros, 2010).

0 indicador ora pesquisado, possibilita também que sejam estabelecidas comparações entre nações e regiões, uma vez que pondera o consumo de recursos, originários das atividades humanas, diante a capacidade de suporte da natureza, de modo a visualizar se os impactos no ambiente global são ou não sustentáveis a longo prazo. Ainda, como ferramenta para que tomadores de decisão, membros da sociedade e gestores públicos e privados possam analisar os ganhos ambientais de um país, uma região ou uma cidade (Cindin e Santos, 2004).

Vários países têm realizado o cálculo da pegada ecológica. De acordo com o sétimo relatório "Planeta Vivo 2008" (WWF, 2008), o índice da PE recomendado para que a biocapacidade do planeta seja suficiente para garantir a 
sustentabilidade é de 2,1 ha/ano por pessoa. 0 Brasil em 2016 tinha a biocapacidade de 2,9 ha por habitante, nível acima do recomentado, mas bem próximo da média mundial $(2,7$ ha por habitante). Em outras palavras se todas as pessoas do planeta tivessem essa pegada, seria necessário 1,6 planeta para sustentar esse padrão de vida (WWF, 2016). Esta tendência fica mais preocupante, pois, de acordo com do relatório "Planeta Vivo 2018", nos últimos 50 anos, a Pegada Ecológica mundial aumentou cerca de 190\% (Grooten e Almond, 2018).

Algumas cidades também têm realizado o cálculo da Pegada Ecológica, a exemplo das Cidades de Taguatinga, Ceilândia e Samambaia, no Distrito Federal (Dias, 2002). Na Região Sul brasileira, Andrade (2006) calculou este índice em Florianópolis, Santa Catarina.

Outros estudos têm realizado a Pegada Ecológica com alunos em instituições educacionais (Paixão et al., 2012; Lamim-Guedes, 2015; Santos et al., 2016), evidenciando como o crescimento populacional a evolução dos hábitos de vida influencia na demanda dos recursos naturais. $O$ cálculo da PE também pode ser realizado individualmente, por meio de um questionário disponibilizado no sitio da Rede Global da Pegada Ecológica (www.footprint.network.org), entidade internacional criada para promover a sustentabilidade, parceira da Rede WWF, que monitora a Pegada Ecológica.

O método da Pegada Ecológica parte de premissas para simplificar os cálculos do indicador. Algumas são listadas a seguir (Wackernagel e Rees, 1996; Chambers et al., 2000; Bellen, 2007):

- Todos os tipos de energia, o consumo de materiais e a descarga de dejetos e resíduos demandam uma capacidade de produção e/ou absorção de uma área com dimensões finitas de terra ou água.

- Os cálculos consideram apenas as receitas mais importantes, determi- nadas por valores econômicos, tecnológicos e socioculturais para a área estudada.

- 0 modelo considera apenas cinco pontos (apropriação de recursos renováveis, extração de recursos não-renováveis, absorção de rejeitos, destruição do solo e depleção de recursos hídricos) como forma de apropriação, direta ou indireta, dos serviços da natureza pela atividade humana; além disso, esse método não contabiliza, em duplicidade, uma área que produz um ou mais desses serviços simultaneamente.

- A maior parte das estimativas realizadas pelo método é fundamentada em médias de consumo nacionais e mundiais de produtividade da terra com 0 objetivo de facilitar comparações entre regiões e países.

- O método adota uma classificação para os dados estatísticos sobre consumo, com base em cinco categorias (alimentação, habitação, transporte, bens de consumo e serviços) com o objetivo de simplificar a coleta de dados.

- Utilização de uma taxionomia simples de produtividade ecológica, atualmente envolvendo cinco categorias de território ou área definida (território de biodiversidade).

Destaca-se que para especificar a área total requerida para suportar determinado padrão de consumo, é preciso estimar a utilização da terra.

Para Bellen (2007, p. 127), no que se refere à pegada ecológica, "[...] os resultados refletem um estado atual e a ferramenta não pretende fazer extrapolações, apenas sensibilizar a sociedade".

Além da pegada ecológica, existem outras formas de medir o impacto da ação antrópica em relação ao seu consumo, como a pegada de carbono e a pegada hídrica. De acordo com Silva et al. (2013), a pegada hídrica tem sido usada como indicador do consumo de água de pessoas (consumo direto) e produtos em diversas partes do mundo (consumo indireto). A pegada hídrica 
depende de algumas características hídricas da região.

A pegada de carbono mede a sustentabilidade ambiental da produção e distribuição de alimentos através da quantificação dos gases de efeito estufa como o dióxido de carbono equivalente ( $\mathrm{CO}_{2}$ eq) (Campos et al., 2019).

Além do cálculo das Pegadas existem diversos outros Indicadores de sustentabilidade, como ESI (Índice de Sustentabilidade Ambiental), EPI (Índice de Performance Ambiental), LPI (Índice Planeta Vivo) e o BIP 2020 (Indicadores de Biodiversidade em Parceria) (Barbosa, 2013).

De acordo com Barbosa (2013)

As metodologias dos diferentes indicadores citados acima expõem a cultura política do monitoramento e gestão dos recursos naturais, mas não explicita as condições de vida dos seres humanos no interior dos processos de mensuração das capacidades físicobiótica dos ecossistemas.

Veiga (2010) comenta que a avaliação da sustentabilidade requer um pequeno conjunto bem escolhido de indicadores. É necessário incluir as três dimensões na construção do índice para que seja medido o desempenho econômico, a qualidade de vida (ou bemestar), e a sustentabilidade do desenvolvimento.

Destaca-se a necessidade de investigar uma medida bem precisa de renda domiciliar disponível, e não de produto e a qualidade de vida deve incorporar até recentes descobertas no ramo da economia da felicidade.

\section{Metodologia}

A metodologia utilizada baseou-se na aplicação do questionário do WWF Brasil (Borba et al., 2007) para calcular a pegada ecológica de 30 discentes matriculados no Curso de Pós-Graduação em Desenvolvimento e
Meio Ambiente, da Universidade Federal do Ceará, no ano de 2018, com seus respectivos consentimentos para divulgação dos resultados. 0 questionário foi formado por 15 perguntas objetivas, onde os entrevistados deveriam escolher as alternativas que melhor representem seus padrões de consumo.

A definição do universo amostral é parte do universo escolhido, selecionado a partir de um critério de representatividade (Vergara, 1997; Vieira, 2008). Assim, foram aplicados questionários com todos os alunos matriculados na disciplina de Indicadores de Sustentabilidade.

As perguntas que compõem o questionário foram a listadas abaixo e cada alternativa tem um peso que varia entre 1 e 12 (Tabela 1):

\section{1) Ao fazer compras no supermercado:}

A) Compro tudo que tenho vontade, sem prestar atenção no preço, na marca ou na embalagem.

B) Uso apenas o preço como critério de escolha.

C) Presto atenção se os produtos de uma determinada marca são ligados a alguma empresa que não respeita o meio ambiente ou questões sociais.

D) Procuro considerar preço e qualidade, além de escolher produtos que venham em embalagens recicláveis e que respeitem critérios ambientais e sociais.

2) Entre os alimentos que normalmente você consome, que quantidade é pré-preparada, embalada ou importada?
A) Quase todos.
B) Metade.
C) Um quarto.
D) Muito poucos. A maior parte dos alimentos que consumo não é pré- preparada nem embalada, tem origem orgânica e é produzida na região onde vivo. 
3) 0 que acontece com o lixo produzido na sua casa?

A) Não me preocupo muito com o lixo.

B) Tudo é colocado em sacos recolhidos pelo lixeiro, mas não faço a menor ideia para onde vai.

C) 0 que é reciclável é separado.

D) O lixo seco é direcionado à reciclagem e o lixo orgânico, encaminhado para a compostagem (transformação em adubo).

4) Que eletrodomésticos você utiliza (escolha a opção que mais se pareça com a situação de sua casa)?

A) Geladeira, freezer, máquina de lavar roupa/tanquinho e forno de microondas.

B) Geladeira e máquina de lavar roupa/tanquinho.

C) Geladeira e forno microondas.

D) Geladeira

5) Você considera, na sua escolha de compras de eletrodomésticos e lâmpadas, informações referentes à eficiência energética do produto (se o produto consome menos energia)?

A) Não. Compro sempre as lâmpadas e os eletrodomésticos que estiverem mais baratos.

B) Utilizo lâmpadas frias, mas não levo em consideração a eficiência energética de eletrodomésticos.

C) Compro eletrodomésticos que consomem menos energia e utilizo lâmpadas incandescentes (amarelas).

D) Sim. Só utilizo lâmpadas frias e compro os eletrodomésticos que consomem menos energia.
6) Você deixa luz, aparelhos de som, computadores ou televisão ligados quando não estão sendo utilizados?

A) Sim. Deixo luzes acesas, computador e TV ligados, mesmo quando não estou no ambiente ou utilizando-os.

B) Deixo a luz dos cômodos ligada quando sei que em alguns minutos vou voltar ao local.

C) Deixo o computador ligado, mas desligo o monitor quando não estou utilizando.

D) Não. Sempre desligo os aparelhos e lâmpadas quando não estou utilizando, ou deixo o computador em estado de hibernação (stand by).

7) Quantas vezes por semana, em média, você liga o ar condicionado em casa ou no trabalho?

A) Praticamente todos os dias.

B) Entre três e quatro vezes.

C) Entre uma e duas vezes por semana.

D) Não tenho ar condicionado.

8) Quanto tempo você leva, em média, tomando banho diáriamente?

A) Mais de 20 minutos.

B) Entre 10 e 20 minutos.

C) Entre 10 e 5 minutos.

D) Menos de 5 minutos.

\section{9) Quando você escova os dentes:}

A) A torneira permanece aberta o tempo todo.

D) A torneira é aberta apenas para molhar a escova e na hora de enxaguar a boca. 
10) Quantos habitantes moram em sua cidade?
A) Acima de 500 mil pessoas.
B) De 100 mil a 500 mil pessoas.
C) De 20 mil a 100 mil pessoas.
D) Menos de 20 mil pessoas.

11) Quantas pessoas vivem na sua casa ou apartamento?
A) 1 pessoa.
B) 2 pessoas.
C) 3 pessoas.
D) 4 pessoas ou mais.

\section{2) Qual é a área da sua casa/ apartamento?}
A) 170 metros quadrados ou mais.
B) De 100 a 170 metros quadrados
(3 quartos).
C) De 50 a 100 metros quadrados
(2 quartos).
D) 50 metros quadrados ou menos
(1 quarto).

13) Com que frequência você consome produtos de origem animal (carne, peixe, ovos, laticínios)?
A) Como carne todos os dias.
B) Como carne uma ou duas vezes por semana.
C) Como carne raramente, mas ovos/laticínios quase todos os dias.
D) Nunca (vegetariano).

14) Qual o tipo de transporte que você mais utiliza?

A) Carro é meu único meio de transporte e, na maioria das vezes, ando sozinho.

B) Tenho carro, mas procuro fazer a pé os percursos mais curtos e privilegio o uso de transporte coletivo sempre que possível.

C) Não tenho carro e uso transporte coletivo.

D) Não tenho carro, uso transporte coletivo quando necessário, mas ando muito a pé ou de bicicleta.

15) Por ano, quantas horas você gasta andando de avião?
A) Acima de 50 horas.
B) 25 horas.
C) 10 horas.
D) Nunca ando de avião.

Tabela 1. Valor de cada questão no questionário da Pegada Ecológica que foi aplicado aos Alunos de Pós-Graduação em Desenvolvimento e Meio Ambiente da Universidade Federal do Ceará (UFC).

\begin{tabular}{|c|c|c|c|c|c|c|c|c|c|}
\hline \multicolumn{2}{|c|}{ Questão 1} & \multicolumn{2}{|c|}{ Questão 2} & \multicolumn{2}{|c|}{ Questão 3} & \multicolumn{2}{|c|}{ Questão 4} & \multicolumn{2}{|c|}{ Questão 5} \\
\hline$a$ & 4 & $\mathbf{a}$ & 4 & a & 4 & $a$ & 4 & $a$ & 4 \\
\hline b & 3 & b & 3 & b & 3 & b & 3 & b & 3 \\
\hline C & 2 & c & 2 & C & 2 & C & 2 & C & 2 \\
\hline d & 1 & d & 1 & d & 1 & d & 1 & d & 1 \\
\hline
\end{tabular}

\begin{tabular}{|c|c|c|c|c|c|c|c|c|c|}
\hline \multicolumn{2}{|c|}{ Questão 6} & \multicolumn{2}{|c|}{ Questão 7} & \multicolumn{2}{|c|}{ Questão 8} & \multicolumn{2}{|c|}{ Questão 9} & \multicolumn{2}{|c|}{ Questão 10} \\
\hline a & 4 & a & 4 & a & 4 & a & 4 & a & 8 \\
\hline b & 3 & b & 3 & b & 3 & b & 3 & b & 6 \\
\hline C & 2 & C & 2 & c & 2 & C & 2 & c & 4 \\
\hline d & 1 & d & 1 & d & 1 & d & 1 & d & 2 \\
\hline
\end{tabular}

\begin{tabular}{|cc|cc|cc|cc|cc|}
\hline \multicolumn{2}{|c|}{ Questão 11 } & \multicolumn{2}{|c|}{ Questão 12 } & \multicolumn{2}{c|}{ Questão 13 } & \multicolumn{2}{c|}{ Questão 14 } & \multicolumn{2}{c|}{ Questão 15 } \\
\hline a & $\mathbf{8}$ & a & $\mathbf{8}$ & a & $\mathbf{8}$ & a & $\mathbf{8}$ & a & 12 \\
\hline b & 6 & b & 6 & b & 6 & b & 6 & b & 9 \\
\hline c & 4 & C & 4 & c & 4 & c & 4 & c & 6 \\
\hline d & 2 & d & 2 & d & 2 & d & 2 & d & 3 \\
\hline
\end{tabular}

Fonte: Borba et al. (2007). 
Ao terminar de responder o questionário realiza-se o somatório de pontos das alternativas selecionadas e posteriormente verifica-se 0 seu enquadramento. As classes são:

- Até 23 pontos: parabéns, sua pegada é excelente.

- De 24 a 44 pontos: vale apena reavaliar algumas opções do seu cotidiano.

- De 45 a 66 pontos: nesse ritmo o planeta não vai aguentar.

- De 67 a 88 pontos indica alerta total.

\section{Resultados e discussão}

0 resultado evidenciou que dos 30 discentes apenas um obteve pontuação menor que 23 pontos (estilo de vida leva em conta a saúde do planeta), o que é recomendado, cinco discentes ficaram com a pontuação entre 24 a 44 pontos (a pegada está um pouco acima da capacidade do planeta), 23 alunos ficaram com a pontuação entre 45 a 66 pontos e um aluno ficou com a pontuação entre 67 a 88 pontos (Figura 1).
$\mathrm{Na}$ Figura 1, observa-se que $3,33 \%$ dos entrevistados (com escore entre 67 e 88 pontos) merecem alerta total em relação ao seu estilo de vida, haja vista que com esse padrão de vida necessita de quatro terras para sobreviver no planeta. Esse tipo de PE está entre os padrões mais insustentáveis do mundo. Afinal, com esse padrão de consumo e hábitos de vida estão causando danos à vida na Terra e ameaçando o futuro. Cerca de $76,68 \%$ dos alunos apresentaram estilos de vida que necessitariam de três terras para sobreviverem, o que significa que neste ritmo o planeta não vai aguentar (Figura 1). Ainda, 16,66\% dos alunos mostraram que suas pegadas estão um pouco acima da capacidade do planeta, necessitando assim de duas terras para sobreviverem, o que significa trazer menos impactos à natureza, que, com alguns ajustes e mudanças, podem leválos a um estilo de vida mais sustentável. Portanto, vale apena reavaliar alguns padrões de consumo e hábitos de vida do seu cotidiano.

\section{Pontuação}

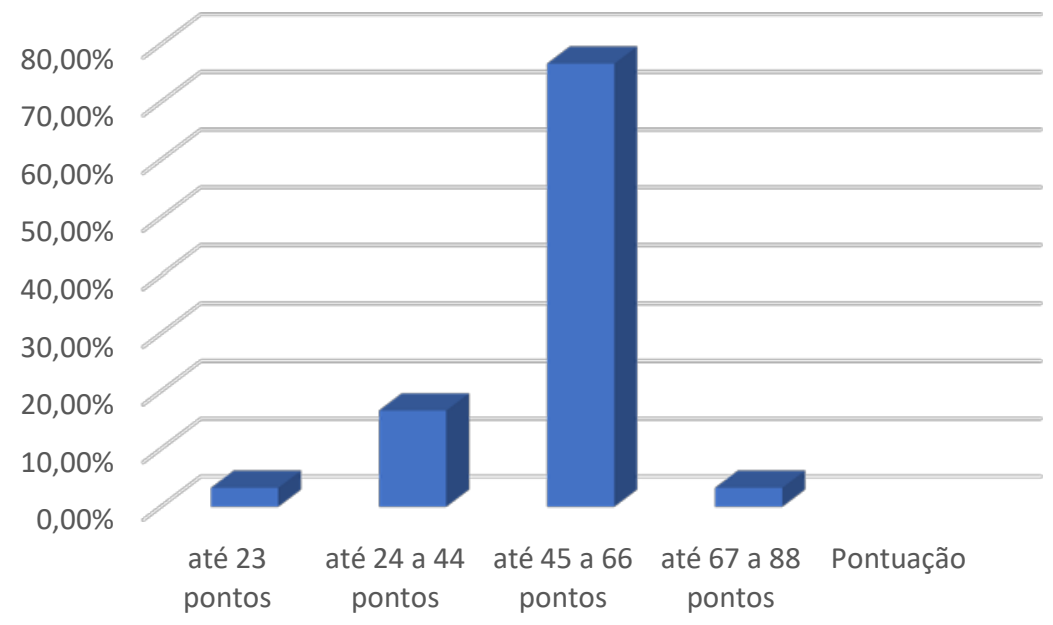

Figura 1. Pegada Ecológica - Porcentagem dos alunos de Pós-Graduação em Desenvolvimento e Meio Ambiente da Universidade Federal do Ceará (UFC). 
Pesquisa de natureza semelhante a esta foi realizada por Santos et al. (2016), cujo resultado mostrou que a maioria dos alunos de terceiro ano do Ensino Médio da Escola Estadual Patriarca da Independência do Distrito de Progresso, Tangará da Serra-MT, também obtiveram pontuação entre 45 a 66 pontos. Observa-se que o etilo de vida não necessariamente está relacionado com o nível de escolaridade. Destaca-se também que a educação ambiental tem um papel fundamental nas escolas podendo influenciar na conduta das pessoas em relação ao meio ambiente.

Sabe-se que a pegada ecológica tem crescido nos últimos anos e sua variação é devida a diferentes estilos de vida e padrões de consumo (Relatório Planeta Vivo, 2018). Ainda analisando a Figura 1, pode-se perceber que a maioria dos alunos $(76,68 \%)$ tiveram pontuação entre 45 e 66. Certamente, os estilos de vida, estão associados ao consumo humano, que tende a aumentar de acordo com a renda, além da maioria dos alunos residirem em grandes cidades, como as capitais ou locais com um número grande de habitantes, estão influenciando a pegada. Estes resultados elevados, corroboram com a hipótese de que o modelo econômico atual e o estilo de vida implicam nos níveis da Pegada Ecológica insustentável, inclusive o consumo de grande quantidade de bens e serviços e dos recursos naturais, que provocam grandes emissões de dióxido.

Observa-se na Figura 2 que o consumo de carne todos os dias por parte dos alunos da UFC é bem significativo, 24 alunos ou $80 \%$ dos discentes revelaram consumir carne todos os dias, enquanto que dois alunos (7\%) disseram comer carne uma ou duas vezes por semana, no entanto quatro alunos $(13 \%)$ disseram consumir carne raramente, mas ovos/laticínios quase todos os dias e nenhum $(0 \%)$ revelou ser vegetariano.

\section{Consumo de Alimentos}

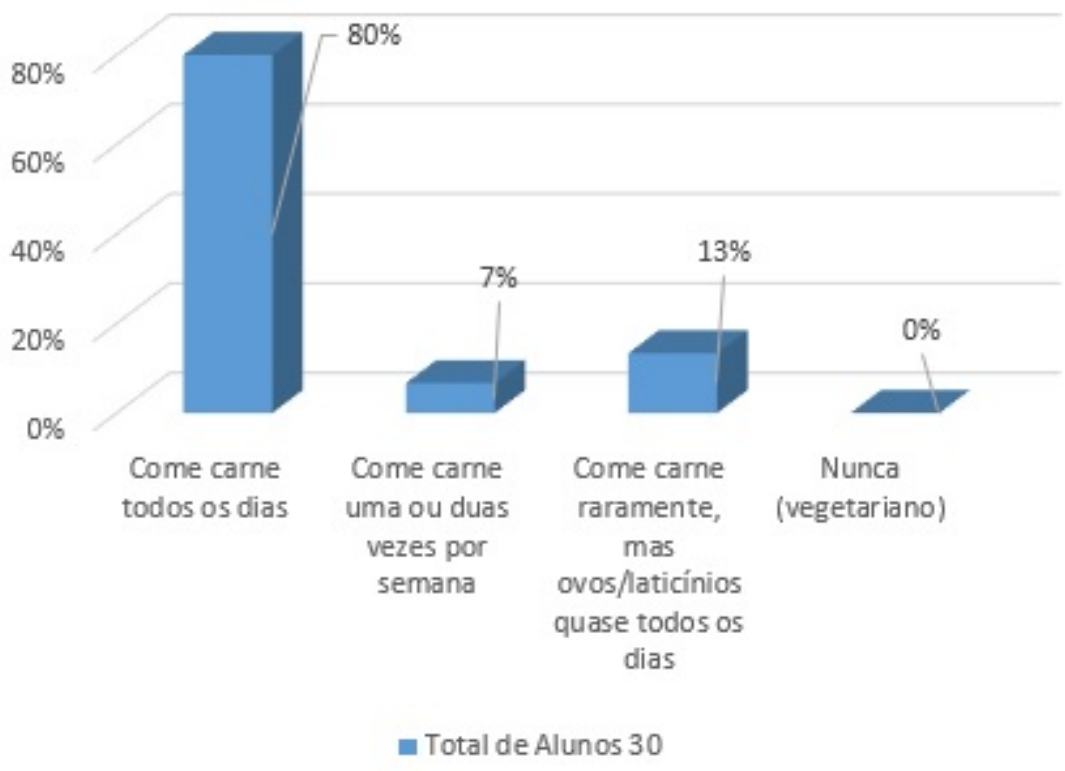

Figura 2. Pegada Ecológica - Frequência do consumo dos produtos de origem animal (carne, peixe, ovos, laticínios.) pelos Alunos de Pós-Graduação em Desenvolvimento e Meio Ambiente da Universidade Federal do Ceará (UFC). 
Em relação às opções que compõem o padrão de consumo dos discentes, pode-se perceber que os dados mostram o consumo de animais, a exemplo de carne, superior aos alimentos vegetais.

De acordo com a Figura 3, observa-se que o transporte particular, a exemplo do carro, é o principal meio de locomoção utilizado pelos alunos. Cerca de $67 \%, 20$ alunos. Somente três alunos
$(10 \%)$ dos discentes disseram ter carro, mas procurava fazer a pé os percursos mais curtos e privilegiava o uso de transporte coletivo sempre que possível. Os alunos que não têm carro e usavam o transporte coletivo correspondia a 5 (17\%). Contudo, dois discentes (7\%) disseram não ter carro, usava o transporte coletivo quando necessário, e, ainda, que andava muito a pé ou de bicicleta.

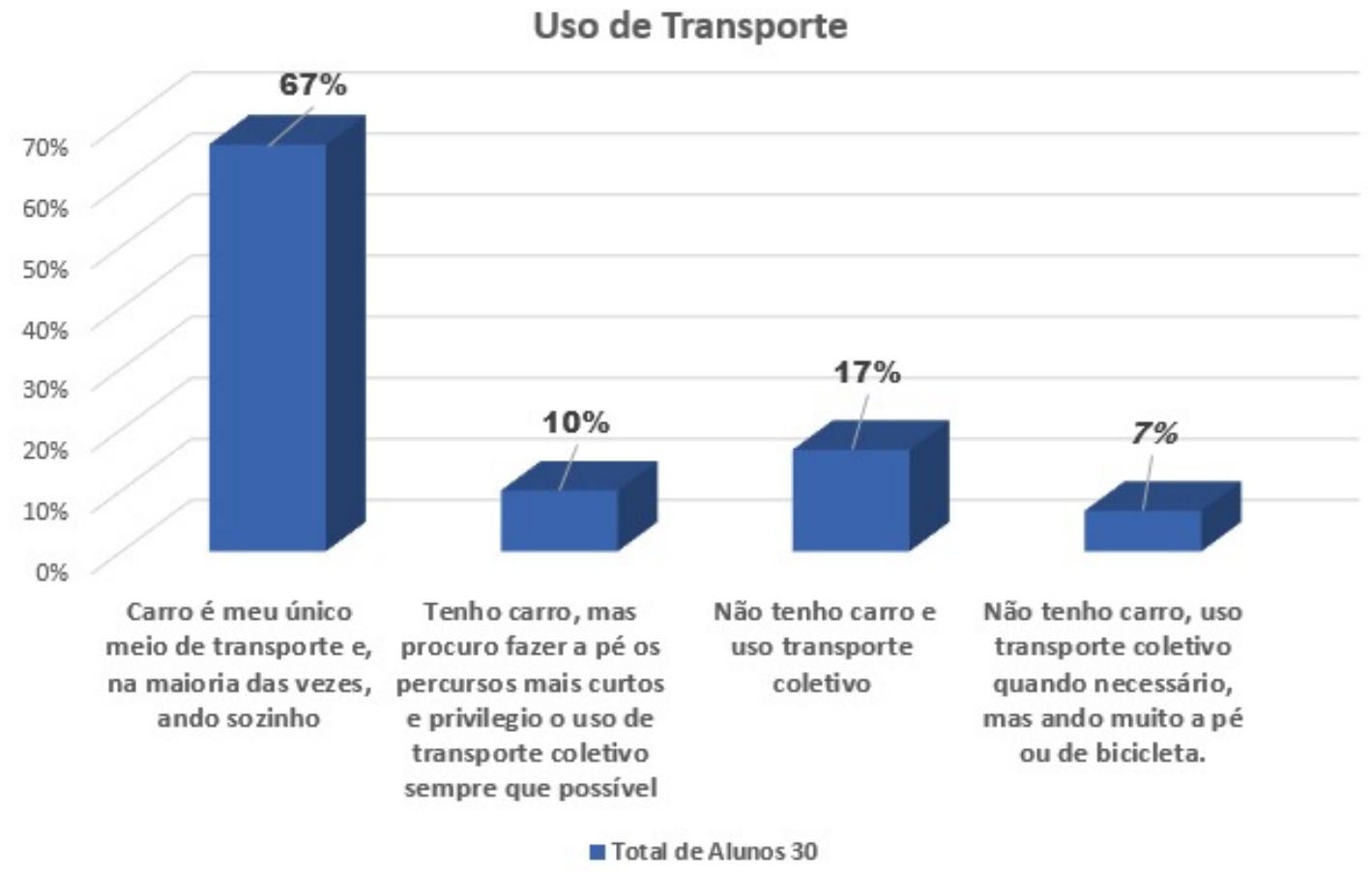

Figura 3. Pegada Ecológica - Tipo de transporte mais utilizado pelos Alunos de Pós-Graduação em Desenvolvimento e Meio Ambiente da Universidade Federal do Ceará (UFC).

Diante das opções que compõem o padrão de uso dos transportes por parte dos alunos, pode-se observar que os dados revelam que o uso de carro somente sendo utilizado por uma pessoa é superior a quem anda a pé, de bicicleta ou faz uso do transporte coletivo.

Quando indagados sobre o que acontecia com o lixo produzido em suas casas, 16 discentes informaram que é reciclado é separado, enquanto o restante optou pela letra "B" que diz: Tudo é colocado em sacos recolhidos pelo lixeiro, mas não faço a menor ideia para onde vai.

Ao serem questionados sobre o quesito do questionário da Pegada Ecológica, que trata da luz elétrica, aparelhos de som, computadores ou televisão ligados quando não estão sendo utilizados, diante das alternativas, 15 discentes fizeram opção pela letra "D" 
que diz o seguinte: Não. Sempre desligo os aparelhos e lâmpadas quando não estou utilizando, ou deixo o computador em estado de hibernação (stand by). 9 alunos responderam pela opção: Deixo o computador ligado, mas desligo 0 monitor quando não estou utilizando. E, 6 alunos optaram pela letra B": Deixo a luz dos cômodos ligada quando sei que em alguns minutos vou voltar ao local.

A comunidade universitária quando questionada sobre quanto tempo leva, em média, tomando banho diariamente, 10 discentes fizeram opção pela letra "d": Menos de 5 minutos. Assim como 10 discentes optaram pela letra " $C$ " no que se refere entre 10 e 5 minutos. Enquanto que 9 alunos optaram pela letra "B" que se refere a entre 10 e 20 minutos. E por fim 1 discente fez a opção da letra "A" que corresponde a mais de 20 minutos a duração do banho.

Por último, foi questionado junto aos referidos discentes sobre quantas pessoas vivem na sua casa ou apartamento, 12 alunos fizeram opção pela letra "D", que afirma 4 pessoas ou mais residem na mesma casa ou apartamento, enquanto isso, 8 alunos disseram que moravam com 3 pessoas, ou seja , optaram pela letra "C". E, 7 discentes optaram pela letra "B", ou seja, moram com 2 pessoas. E, por fim, 3 discentes optaram pela letra " $A$ ".

O sistema capitalista adotado pelas sociedades urbanas induz a um alto padrão de consumo, que mesmo ao alcance de poucos, traz desequilíbrios insustentáveis pelos danos que causa ao meio ambiente. Diante desse resultado, Gomes (2006) argumenta que para que o desenvolvimento seja norteado no sentido da sustentabilidade é necessário adotar a visão de mundo biocêntrica, comprometida com todas as formas de vida na Terra.

Acredita-se que há uma crise ambiental. Mas, não é o meio ambiente natural que se encontra em crise, e sim a humanidade que vive uma crise de valores, que gera os problemas presentes em diferentes setores de nossa sociedade e ameaçam ao meio ambiente (Gomes, 2006).

Neste sentido, é preciso buscar uma nova ética, norteada por um sentimento de pertença mútua entre todos os seres. A ética pode auxiliar, principalmente, na interrelação do homem com o planeta, proporcionando assim, uma relação equilibrada entre a natureza e o ser humano (Sirvinskas, 2002). Sem a mudança de valores e posteriormente da postura da sociedade, e nesse caso dos alunos, não há como vivermos de acordo com a biocapacidade ecológica que o planeta pode suportar e assim não alcançaremos os objetivos da sustentabilidade (Leff, 2001).

Ao escolher a ética da sustentabilidade, os discentes deverão reavaliar seus valores e alterar seu comportamento em relação ao padrão de consumo. Esse processo requer sensibilização, mobilização social e informação (Gomes, 2006).

Para isso é fundamental a educação do consumidor, já que grande parte dos problemas ambientais presentes vêm de padrões impostos pelo sistema capitalista, por meio da publicidade, que impulsiona o consumo humano descontrolado (Avelar, 2010). Isso por sua vez, gera a uma maior demanda por áreas de terras, impondo um estilo de vida insustentável. Nesse caso, vale ressaltar que embora todos os entrevistados tenham nível superior, os valores do índice abordado foram altos para a maioria dos entrevistados. Nesse sentido, educação e cidadania são indissociáveis, pois um cidadão educado, em todos os níveis, será capaz de lutar, exigir seus direitos e cumprir seus deveres (Canepa, 2004).

A partir da formação de uma nova consciência, sensível as questões do planeta é possível uma mudança de hábitos e algumas práticas podem auxiliar a reduzir a pegada ecológica como: consumir alimentos vegetais da estação produzidos localmente, produtos nacionais e provenientes da agricultura orgânica, ajudam a manter o equilíbrio 
entre o que a Terra nos fornece e o que consumimos (Borba et al., 2007).

Plantar alimentos, no quintal, em hortas comunitárias ou em qualquer local em residências, irrigando-as sem desperdiçar, podem ajudar a diminuir sua Pegada Ecológica. Recomenda-se ter uma dieta com baixo consumo diário de proteína animal, pois uma alimentação rica em carnes contribui para a exaustão de vários recursos, como a água $(60 \%$ da água doce da Terra é empregada no cultivo de alimentos, sendo uma maior porção na produção de carnes). Além disso, é necessário consumir de forma responsável, visando a sustentabilidade, reduzindo produtos "descartáveis" ou que agregam alta tecnologia, pois estes contribuem para o esgotamento das reservas naturais do planeta e realizar o descarte das embalagens em locais adequados, seja para reciclagem, para produzir adubo orgânico, dentre outra (Borba et al., 2007).

Observando os resultados, é preciso adotar uma nova postura, fundamentada na ética ambiental para impedir um colapso dos recursos naturais e assim vivermos de acordo com a biocapacidade ecológica que o planeta pode suportar.

\section{Conclusão}

Pode-se perceber a grande importância de calcular a pegada ecológica para ter uma estimativa sobre o padrão de consumo e hábitos de vida a um estilo sustentável em prol da qualidade de vida das pessoas hoje e no futuro. Portanto, a utilização deste indicador pode ser uma forma inicial de sensibilizar cada pessoa em diversos contextos sociais.

Verificou-se nesta pesquisa que a maioria dos discentes que responderam o questionário precisam fazer uma reavaliação dos seus hábitos de consumo.
Vários fatores podem ter influenciado neste resultado como a cultura local, a acessibilidade aos produtos consumidos de forma mais fácil e corriqueiro, a despreocupação com as gerações futuras, entre outros.

Acredita-se que as palavras-chave desse processo são sensibilização, mobilização social e mudança de hábitos. É importante ampliar as discussões sobre a importância de novos hábitos de consumo para promover a mudança de atitudes dos consumidores e da sociedade em geral.

\section{Conflito de interesses}

As autoras declaram não haver conflito de interesses.

\section{Referências}

Andrade, B. B. Turismo e sustentabilidade no Município de Florianópolis: uma aplicação do Método da Pegada Ecológica. Florianópolis: Universidade Federal de Santa Catarina, 2006. (Dissertação de mestrado).

Avelar, A. E. S. Fatores de influência no consumo de alimentos e alimentação fora do lar. Lavras: Universidade Federal de Lavras, 2010. (Dissertação de Mestrado em Administração).

Barbosa, E. B., Pimenta, H. F. S., Castro, A. P. Indicadores de sustentabilidade $\mathrm{e}$ sua dimensão ambiental: ESI, EPI, LPI, pegada ecológica, BIP 2020. DELOS: Desarrollo Local Sostenible, v. 6, n. 18, 2013. Disponível em: <http://www.eumed.net/rev/delos/ 18/pegada-ecologica.html>. Acesso em: 23 jul. 2019.

Bellen, H. M. Indicadores de sustentabilidade: uma análise comparativa. Rio de Janeiro: Editora FGV, 2007.

Borba, M. P.; Costa, L.; Valente, M.; Falcão, A. Pegada ecológica: que marcas queremos deixar no planeta? Brasília: WWF Brasil, 2007. Disponível em: <http://assets.wwf.org. br/downloads/19mai08_wwf_pegada.pdf>. Acesso em: 11 jan. 2019. 
Campos, S.; Weinschutz, R.; Cherubini, E.; Mathias, A. L. Avaliação comparativa da pegada de carbono de margarina e manteiga produzidas no Sul do Brasil. Engenharia Sanitaria e Ambiental, v. 24, n. 1, 2019. https://doi.org/10.1590/s1413-415220 19178908

Canepa, C. Educação ambiental: ferramenta para a criação de uma nova consciência planetária. Revista de Direito Constitucional e Internacional, v. 12 , n. 48, p. 158-166, 2004.

Chambers, J. Q.; Santos, J.; Ribeiro, R. J.; Higuchic, N. Tree damage, allometric relationships, and above-ground net primary production in Central Amazon Forest. Forest Ecology and Management, v. 152, n. 1/3, p. 73-84, 2000. https://doi.org/10.1016/ S0378-1127(00)00591-0

Cindin, R. P. J.; Silva, R. S. Pegada ecológica: instrumento de avaliação dos impactos antrópicos no meio natural. Estudos Geográficos, v. 2, n. 1, p. 43-52, 2004.

Dias, G. F. Pegada ecológica e sustentabilidade humana. São Paulo: Gaia, 2002.

Firmino, A. M.; Santos, H. N. Pina, J. H. A.; Rodrigues, P. O.; Fehr, M. A relação da pegada ecológica com o desenvolvimento sustentável: cálculo da pegada ecológica de Toribaté. Caminhos de Geografia, v. 10, n. 32, p. 41-56, 2009.

Gomes, D. V. Educação para o consumo ético e sustentável. Revista Eletrônica do Mestrado em Educação Ambiental, v. 16, p. 18-31, 2006.

Grooten, M.; Almond, R. E. A. Relatório Planeta Vivo - 2018: uma ambição maior. Gland, Suíça: WWF, 2018. Disponível em: <https://d3nehc6yl9qzo4.cloudfront.net/do wnloads/lpr_2018_summary_portugues_digit al.pdf>. Acesso em: 20 dez. 2018.

Guimarães, R. P. A assimetria dos interesses compartilhados: América Latina e a agenda global do meio ambiente. In: Leis, H. R. (Org.). Ecologia e política mundial. Petrópolis: Vozes, 1991.

Lamim-Guedes, V. Pegada ecológica como recurso didático em atividades de educação ambiental on-line. Educação Unisinos, v. 19, n. 2, p. 283-289, 2015. https://doi.org/ 10.4013 /edu.2015.192.12
Leff, E. Saber ambiental: sustentabilidade, racionalidade, complexidade, poder. 3. ed. Petrópolis: Vozes, 2001.

Lisboa, C. K.; Barros, M. V. F. A pegada ecológica como instrumento de avaliação ambiental para a Cidade de Londrina. Revista Confins, n. 8, p.1-20, 2010. https://doi.org/10.4000/confins.6395

Paixão, S.; Sá, N.; Viana, J.; Simões, I. Pegada ecológica de uma instituição do ensino superior portuguesa. Revista de Geografia e Ordenamento do Território, n. 1, p. 165180, 2012. https://doi.org/10.17127/got/ 2012.1.008

Santos, D. S.; Portela, M. J. L.; Ferreira, U.; Franke, L. R.; Rocha, E. S. Medição de pegada ecológica com alunos de ensino médio do Distrito de Progresso em Tangará da SerraMT. Anais da $1^{\mathrm{a}}$ Jornada Científica do Instituto Educacional Sem Fronteiras - IESF, Pontes e Lacerda, 2016. p. 13-96.

Silva, V. P. R.; Aleixo, D. O.; Dantas Neto, J.; Maracajá, K. F. B.; Araújo, L. E. Uma medida de sustentabilidade ambiental: pegada hídrica. Revista Brasileira de Engenharia Agrícola e Ambiental, v. 17, n. 1, p. 100-105, 2013. https://doi.org/10.1590/S141543662013000100014

Sirvinskas, L. P. Meio ambiente e cidadania. Revista do Instituto de Pesquisas e Estudos, n. 35, p. 305-307, 2002.

Veiga, J. E. Indicadores de sustentabilidade. Estudos Avançados, v. 24, n. 68, p. 39-52, $2010 . \quad$ https://doi.org/10.1590/S010340142010000100006

Vergara, S. C. Projetos e relatórios de pesquisa em administração. 3. ed. São Paulo: Atlas, 1997.

Vieira, S. Introdução à bioestatística. 4. ed. Rio de Janeiro: Elsevier, 2008.

Wackernagel, M.; Rees, W. Our ecological footprint: Reducing human impact on the Earth. Philadelphia: New Society Publishers, 1996.

WWF. Pegada brasileira. 2008. Disponível em: <https://www.wwf.org.br/natureza_ brasileira/especiais/pegada_ecologica/pegad a_brasileira>. Acesso em: 20 dez. 2018. 
WWF. Pegada Ecológica? O que é isso? 2016.

Disponível em: <https://www.wwf.org.br/ natureza_brasileira/especiais/pegada_ecolog ica/overshootday2>. Acesso em: $29 \mathrm{dez}$. 2018.

CC Informação da Licença: Este é um artigo Open Access distribuído sob os termos da Licença Creative Commons Attribution, que permite uso irrestrito, distribuição e reprodução em qualquer meio, desde que a obra original seja devidamente citada. 